\title{
Feasibility and Efficacy of BLE Beacon IoT Devices in Inventory Management at the Shop Floor
}

\author{
Ravi Ramakrishnan, Loveleen Gaur, Gurinder Singh
}

AIBS, Amity University, India

\begin{tabular}{l} 
Article Info \\
\hline Article history: \\
Received Apr 11, 2016 \\
Revised Jun 1, 2016 \\
Accepted Jun 19, 2016
\end{tabular}

\section{Keyword:}

Android

Bluetooth

Internet of things

Inventory

Location tracking

Low energy beacons

Manufacturing warehouses

\begin{abstract}
Inventory Management is a key area for customer service and cost optimization in any manufacturing setup. As companies turn global and have thousands of components and hundreds of warehouses the inventory becomes a nightmare and a lot of time is spend in tracking inventory and ensuring right shipments. Traditional systems of robotic arms for inventory pick and drop have been based on premises of marking areas of the warehouse and tracking it. However with the advent of IoT all this is set to change as inventory objects become more self-aware and self-broadcasting. This paper technically suggests an approach of managing inventory using low energy blue tooth beacons and also does a statistical case research on two groups of the same organization one before the pilot run where traditional barcode scanners are used to track inventory and other one where the pilot trial BLE beacon technology was used. Statistically the IoT-beacon users are much more efficient and accurate and save lot of time and costs in the short run itself.
\end{abstract}

Copyright (C) 2016 Institute of Advanced Engineering and Science. All rights reserved.

\section{Corresponding Author:}

Ravi Ramakrishnan,

Amity University,

381-A, Regent, Shipra Suncity, Indrapuram, Ghaziabad 201014, Uttar Pradesh, India.

Email: ravi.ramakrishnan@gmail.com

\section{INTRODUCTION}

Inventory Control in shop floors is necessary in production systems which are complex structurally and process wise [1]. Inventory control policies need to be adopted in shop floor, production network, logistics and stores or warehouses. Inventory management influences decision-making in almost all firms and has been extensively studied in the academic and corporate spheres [2].

A conceptual framework of inventory management focussing on low consumption and pattern of demand has statistically existed [3]. However in continuous manufacturing focussing on export sales it may become imperative to stock finished goods till the time of container shipment arrives and cannot be avoided.

Traditionally inventory control systems are a combination of physical cycle counting and enterprise resource planning automation systems which are IT driven. The traditional approach to tag inventory items has been either as a bar code sticker or a RFID tag. RFID has had a lot of positive impact on business operations and is predominant technology in the shop floor global [4].

However with the advent of Internet of Things as a global network allowing communication between objects-objects and objects-humans which is anything in the world by providing unique identity to each and every objects new technology horizons have opened up which is being proposed in this paper [5].

Bluetooth beacons are basically sensors embedded with Bluetooth trans-receivers which can send and receive bi-directional information and are powered by small Li-on batteries and have with advancements become more and lower energy consuming. BLE Beacons have become the front runners for creating contextual and location based experiences for customers as part of forward thinking strategies tailor made to a customer [6]. 


\section{PROPOSED SOLUTION}

In the proposed solution we have done a pilot trial in a process manufacturing company warehouse shed spread over 3600 square meters (60 meters X 60 meters). The solution consists of the following subsystems.

- Subject matter to be tracked consists of large size polyester flexible packaging rolls wound on a thick paper hollow core in a cylindrical format which have different combination of dimensions: Length of wound material 3000-4500 meters, diameter up to 0.5 -1 meter, width ranging from 1-2 meters and microns of each layer of film from $8 \mathrm{~mm}-12 \mathrm{~mm}$.

- BLE beacons with internal batteries and supporting configurable ranges (tap mode i.e. no distance between detector and beacon, near proximity mode around 1 meter between detector and beacon and far proximity mode ( 1 meter to 25 meters). The BLE beacons come with coin cells which have a shelf life over 2 years of continuous running. The beacons have inbuilt sensors for temperature and pressure monitoring which however do not form part of the current solution (Estimote BLE).

- Android based Bluetooth reader tablets placed across the warehouse to detect incoming BLE beacon signals and register presence or absence or track any movements of the BLE beacon. These tablets are placed at intervals of 20 meters each. Each of the scanners has a fixed location and is assigned a fixed coordinate.

- Android application to transmit information to a database for further analysis and reporting on the beacon and their movement trajectory.

The solution starts at the manufacturing start where the subject matter is produced and wound on cores using winders. The BLE beacon is placed inside the core and mapped to each role identity in the IT systems. From here as and when the rolls and corresponding beacons are moved by cranes or forklifts the nearest Bluetooth fixed scanners catch the signal. The strength of the signal averaged over a time interval of 5 seconds is used to triangulate the position of the roll and its distance from the scanners. This way the roll is mapped on a map of the warehouse layout and its entire movement is tracked.

Our simulation has ascertained previous research study findings that smartphones reliably report BLE measurements with RSS values as low as $-100 \mathrm{dBm}$ [2]. Since the warehouse is opens we did not observe any loss of signal due to walls. Also the placement of the roll and the Bluetooth reader at a height of 2 meters further avoided any signal change due to human obstruction.

\section{RESEARCH METHOD}

Limited scholarly articles exist on the BLE beacon technology and its application. It has been specified Bluetooth as a set of specifications for common short range applications , traditionally Bluetooth is connection oriented and peak transmit current is 25mA which is higher for small coin cells [7].

Bluetooth low energy is a new radio protocol stack and enables the IoT with features low latency and fast transactions. The range varies from 150 meters to a max current drawn of $15 \mathrm{~mA}$ with a sleep current of $1 \mathrm{uA}$. BLE is not meant for streaming of data and has a max rate of $1 \mathrm{MBps}$ and can send small locational data.

Earlier study has explained the accuracy of Bluetooth low energy for indoor positioning applications. BLE for proximity detection also provides possibilities of positioning. As per previous studies while indoor positioning using WiFi can give accuracy up to a few meters but it is power hungry while BLE working in the same band $2.4 \mathrm{GHz}$ is efficient as a machine to machine protocol for short messages. Earlier study also explained the influence of human body obstruction on the accuracy of positioning but concludes with establishing the possibility of having BLE accuracy more than WiFi when it comes to positioning by having many beacons [2].

Contextual information is of great relevance in Inventory tracking using positioning applications [8]. In traditional interactive computing, users have a poor mechanism for providing input to computers. Consequently, computers are not currently enabled to take full advantage of the context of the humancomputer dialogue. Using BLE beacons and IoT we can improve the computer's access to context making it possible to produce useful computational services. 


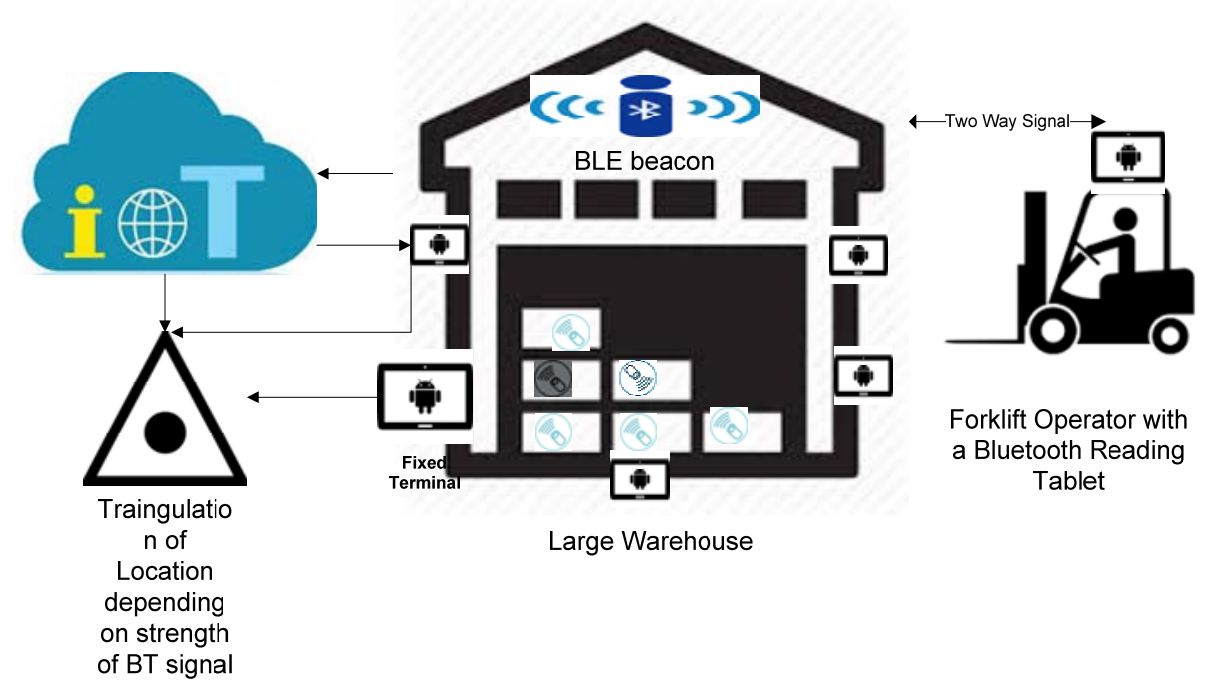

Figure 1. Architectural Diagram for the BLE -Beacon Implementation

\section{RESULTS AND ANALYSIS}

The above mix of technology prototyping and a statistical survey for the acceptance of such a concept has resulted in establishing technical feasibility to establish an inventory management system using the IoT technology which has the potential to further be scaled up for other types of asset monitoring and logistics monitoring, vehicle monitoring, theft detection , transport management and many others. The statistical survey has indicated that the pilot run has shown a decrease in inventory tracking and also improved efficiency.

\subsection{Sample Size, Survey methods and Scales}

To understand the efficiency of the proposed solution using observation methods on locations of the company was taken one where the solution was piloted for two months and we made note of around 25 observations before and after the solution was implemented of two forklift operators who were directly involved in inventory and logistics management and movement at a specific shift time. One was to detect the material using the current barcode scanner program or using manual guidance while the other was equipped with a tablet providing the exact location based on the BLE beacon.

The following steps were taken

- The dependant variables are on a continuous scale namely time to detect a roll (time in minutes rounded off) and accuracy of a roll being identified by the forklift operator e.g. is he picks up a wrong roll on attempt 1st and the right roll in attempt 2nd it will be considered .5 accuracy but if he picks up the correct roll in 1st attempt its accuracy is 1.

- Independent variable is a matched pair that is it remains same for both before and after scenario.

- No significant outliers are observed.

- Approximately normal values are verified using Shapiro-Wilk test of normality. levels).

The following hypotheses were drawn up (given the collected sample results at 95\% confidence

HA0: Null Hypothesis” There is no difference in efficiency in time of detecting an inventory by introducing the BLE beacon technology.

HA1: Alternate Hypothesis” There is significant difference in efficiency in time of detecting an inventory by introducing the BLE beacon technology.

HB0: There is no difference in the accuracy of information i.e. retrieving the correct roll by forklift operator by introducing the BLE beacon technology.

HB1: There is a significant difference in the accuracy of information i.e. retrieving the correct roll by forklift operator by introducing the BLE beacon technology.

\subsection{Statistical Tests}

We first find out if the survey response data is normally distributed for the above two points being considered. For the first question we draw the test of normality of the data as below. 
Table 1. Tests of Normality

\begin{tabular}{llcccccc}
\hline & \multirow{2}{*}{ Before After } & \multicolumn{3}{c}{ Kolmogorov-Smirnova } & \multicolumn{3}{c}{ Shapiro-Wilk } \\
& & Statistic & df & Sig. & Statistic & df & Sig. \\
\hline Average Time Detect & AFTER & .208 & 25 & .007 & .844 & 25 & .001 \\
& BEFORE & .254 & 25 & .000 & .769 & 25 & .000 \\
Average Accuracy Percent & AFTER & .506 & 25 & .000 & .445 & 25 & .000 \\
& BEFORE & .506 & 25 & .000 & .445 & 25 & .000 \\
\hline
\end{tabular}

a. Lilliefors Significance Correction

The Shapiro-Wilk Test is more appropriate for small sample sizes ( $<50$ samples). Since the sig value is 0 hence it is below 0.05 , the data significantly deviate from a normal distribution and there is lot of skewness in both groups of data. Since the data is not normally distributed we cannot go for parametric tests (means) and hence we will go for the non-parametric tests (medians) [9].

We will use the Wilcoxon signed-rank test for two related samples since our data is not normal distribution and the sample collection if of same set of people before and after the change [10].

\subsection{Testing Hypothesis HA}

We run the tests in SPSS for the observations collected before and after the implementation of the BLE Beacon technology. The result shows an improvement in the mean score and a decrease if the maximum time taken with a decrease in the standard deviation between times.

Table 2. Descriptive Statistics

\begin{tabular}{ccccccccc}
\hline & N & Mean & $\begin{array}{c}\text { Std. } \\
\text { Deviation }\end{array}$ & Minimum & Maximum & $\begin{array}{c}\text { Percentiles } \\
\text { 25th }\end{array}$ & 50th (Median) & 75 \\
& & & & & 1.00 & 15.00 & 1.5000 & 2.5000 \\
\hline Before Time Detect Inventory & 25 & 4.1400 & 3.93309 & 5.5000 \\
After Time Detect Inventory & 25 & 1.8080 & .82205 & 1.00 & 4.00 & 1.0000 & 2.0000 & 2.0000 \\
\hline
\end{tabular}

Table 3. Ranks

\begin{tabular}{|c|c|c|c|c|}
\hline & & $\mathrm{N}$ & Mean Rank & Sum of Ranks \\
\hline After Time Detect Inventory - & Negative Ranks & $14^{\mathrm{a}}$ & 9.46 & 132.50 \\
\hline \multirow[t]{3}{*}{ Before Time Detect Inventory } & Positive Ranks & $3^{b}$ & 6.83 & 20.50 \\
\hline & Ties & $8^{c}$ & & \\
\hline & Total & 25 & & \\
\hline
\end{tabular}

The above ranks indicate that fourteen cases saw a drop in timings while three cases saw an increase in timing and eight had near about the same timings.

Table 4. Test Statistics

\begin{tabular}{lc}
\hline & $\begin{array}{c}\text { After Time Detect Inventory - } \\
\text { Before Time Detect Inventory }\end{array}$ \\
\hline $\mathrm{Z}$ & $-2.656^{\mathrm{b}}$ \\
Asymp. Sig. (2-tailed) & .008 \\
\hline a. Wilcoxon Signed Ranks Test \\
b. Based on positive ranks.
\end{tabular}

The test statistics table shows that $\mathrm{Z}$ has a value $<-1.96$ for $\mathrm{p}=.05$ hence we reject the null hypothesis HA0.

\subsection{Testing Hypothesis $\mathrm{HB}$}

We run the tests in SPSS using the data gathered for accuracy of retrievals. 
Table 5. Descriptive Statistics

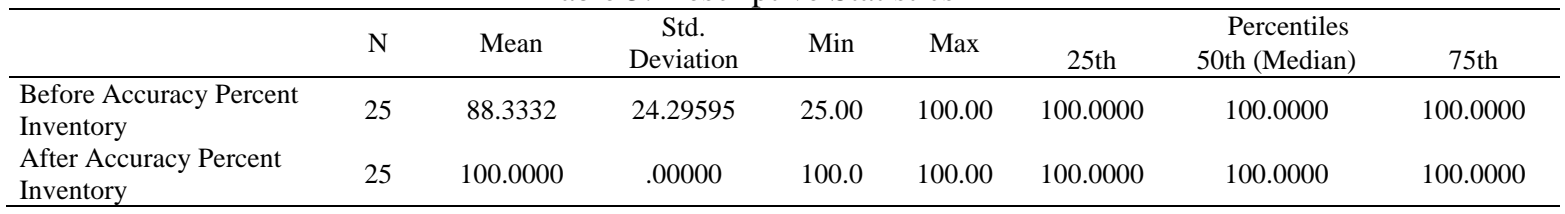
introduction.

There is a change in the mean scores and the minimum scores before and after the BLE beacon

Table 6. Ranks

\begin{tabular}{lllll}
\hline & & $\mathrm{N}$ & Mean Rank & Sum of Ranks \\
\hline After Accuracy Percent Inventory - & Negative Ranks & $0^{\mathrm{a}}$ & .00 & .00 \\
Before Accuracy Percent Inventory & Positive Ranks & $5^{\mathrm{b}}$ & 3.00 & 15.00 \\
& Ties & $20^{\mathrm{c}}$ & & \\
& Total & 25 & \\
& & \\
\hline a. AfterAccuracyPercentInventory $<$ BeforeAccuracyPercentInventory & \\
b. AfterAccuracyPercentInventory > BeforeAccuracyPercentInventory & \\
c. AfterAccuracyPercentInventory = BeforeAccuracyPercentInventory &
\end{tabular}

The positive ranks showed five cases where accuracy has increased and twenty cases where it is similar and there are no cases where accuracy has decreased.

Table 7. Test Statistics ${ }^{\mathrm{a}}$

\begin{tabular}{lc}
\hline & $\begin{array}{c}\text { After Accuracy Percent Inventory - } \\
\text { Before Accuracy Percent Inventory }\end{array}$ \\
\hline $\mathrm{Z}$ & $-2.060^{\mathrm{b}}$ \\
Asymp. Sig. (2-tailed) & .039 \\
\hline a. Wilcoxon Signed Ranks Test & \\
b. Based on negative ranks. &
\end{tabular}

The $\mathrm{z}$ value is $<-1.96$ at $\mathrm{p}<.05$ hence we reject the null hypothesis and conclude an improvement in accuracy of tracking inventory.

\subsection{Analysis}

The literature research, current study and data gathered shows that there could have been three approaches for indoor positioning namely Wi-Fi, Bluetooth or GPS. While GPS in indoor positioning has not been successful the cost of Wi-Fi sensors to be fitted at each inventory item seems to be very high. Also the power consumption of Wi-Fi devices make it necessary for any Wi-Fi client to be constantly powered by auxiliary sources which is very difficult in case of moving inventory items.

\subsection{Comparing Approaches}

Though the use of similar approach of BLE devices seems to be very rare due to the advent of this technology only in the last two years, there has been some study and implementation of BLE for indoor positioning [11]. The following positioning methods have been considered and compared in our research: Angle of Arrival (AOA), Cell Identity (CI), and Time of Arrival (TOA), Time Difference of Arrival (TDOA), and RX power level. Our study validates the earlier finding that all the above parameters in combination help pinpoint the accuracy levels of the BLE beacon. Similarly the use of BLE beacons in managing moving inventory is a very less researched topic and one of the most innovative uses of BLE beacons. This is highlighted by the above findings on increased productivity. No comparative with earlier work is possible due to the less explored nature of this solution.

\section{CONCLUSION}

The above mix of technology prototyping and a statistical survey for the acceptance of such a concept has resulted in establishing technical feasibility to establish an inventory management system using 
the IoT technology which has the potential to further be scaled up for other types of asset monitoring and logistics monitoring, vehicle monitoring, theft detection, transport management and many others. The statistical survey has indicated that the pilot run has shown a decrease in inventory tracking and also improved efficiency.

The IoT concept aims at making the internet even more immersive and pervasive but it is very difficult to build a general architecture for the IoT because of large number of devices, link layer technologies and services [12]. Similar framework studies have suggested the success in location based IoT sensors in cases like elderly life style management and care which can gather data for further analysis and prediction, the same seems to be useful in the context of inventory management as well [13]. The server analyzes and reports the daily activities and activity patterns of inventory movement and forklift operations. In addition, unexpected emergency situations can be estimated and prevented through analysis of the activity information.

While the technology above considers only a limited role of detection by BLE sensors, a combination of low power CPU models like Cortex-M0 which is low power hungry and uses smaller gate counts with the BLE can help avoid round trip data to the servers and reduce load of computing on central resources while managing peer to peer object pairing for faster results [14].

Smart Manufacturing can help companies gather and consolidate data at each step of their operations to get meaningful insights for proactive decision making [15]. Smart Manufacturing combined with Smart Inventory management can help reduce costs and increase customer service quality many folds.

The paper leaves scope for further research in both the technology front and the management area of statistically finding acceptability levels of the technical model. The technology model needs to be tested considering different warehouse layouts and obstacles or radio interferences to BLE devices. The samples could have been drawn from a skewed distribution due to convenience nature of sampling hence a more elaborate study of a larger sized sample with distribution will be advised as the next step for further research.

\section{ACKNOWLEDGEMENTS}

The initial idea for the research was generated post a study of a routine problem of Indian process manufacturing companies of physical stock not matching with the system stock balances and due to the continuous nature of movement of material to and from inventory due to round the clock operations physical counting required down time leading to productivity losses. We are also strongly indebted to the Indian company who helped us implement the trial run and also take statistical measurements to ensure it was successful.

\section{REFERENCES}

[1] B. S. Reiter, et al., "Inventory Control in Shop Floors, Production Networks and Supply Chains Using System Dynamics, Konferenzband zur 12. ASIM Fachtagung "Simulation in Produktion und Logistik",” SCS Publishing House e.V, Erlangen, pp. 273-282.

[2] R. Faragher and R. Harle, "An Analysis of the Accuracy of Bluetooth Low Energy for Indoor Positioning Applications,” 2010. Retrieved from http://www.cl.cam.ac.uk/ rmf25/papers/BLE.pdf.

[3] P. Wanke, "A Conceptual Framework for Inventory Management: Focusing on Low-Consumption Items," Production and inventory management journal, vol/issue: 49(1), 2014.

[4] E. W. T. Ngaia, et al., "RFID research: An academic literature review (1995-2005) and future research directions," International Journal of Production Economics, vol/issue: 112(2), pp. 510-520, 2008.

[5] R. Aggarwal and M. L. Das, "RFID Security in the Context of Internet of Things," First International Conference on Security of Internet of Things, Kerala, 17-19 August, pp. 51-56, 2012. http://dx.doi.org/10.1145/2490428.2490435.

[6] M. Moody, “Analysis of Promising Beacon Technology for Consumers,” The Elon Journal of Undergraduate Research in Communications, vol/issue: 6(1), 2015.

[7] J. Decuier and IEEE, "Bluetooth 4.0 Low energy," http://chapters.comsoc.org/vancouver/BTLER3.pdf.

[8] A. K. Dey, "Understanding and using context," Springer London Personal and ubiquitous computing journal, vol/issue: 5(1), pp. 4-7, 2001.

[9] J. Murray, "Likert Data: What to Use, Parametric or Non-Parametric?," International Journal of Business and Social Science, vol/issue: 4(11), 2013.

[10] J. D. Winter, et al., "Five-Point Likert Items: t test versus Mann-Whitney-Wilcoxon,” in Research Gate, 2010.

[11] K. C. Cheung, et al., "An Inexpensive Bluetooth-Based Indoor Positioning Hack,” Massachusetts Institute of Technology.

[12] A. Zanella, et al., IEEE Internet of Things Journal , vol/issue: 1(1), 2014

[13] H. S. Kim, et al., "A Daily Activity Monitoring System for Internet of Things-Assisted Living in Home Area Networks," International Journal of Electrical and Computer Engineering (IJECE), vol/issue: 6(1), pp. 399-405. 
[14] S. D. Kim and S. E. Lee, "Little Core Based System on Chip Platform for Internet of Thing," International Journal of Electrical and Computer Engineering (IJECE), vol/issue: 5(4), pp. 695-700, 2015.

[15] Ramakrishnan R. and Gaur L., "Application of Internet of Things (IoT) for Smart Process Manufacturing in Indian Packaging Industry,” Advances in Intelligent Systems and Computing,Springer, pp. 339-346, 2016.

\section{BIOGRAPHIES OF AUTHORS}

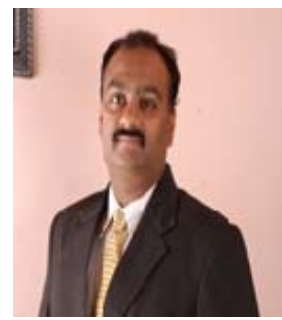

Ravi Ramakrishnan is an MBA from Faculty of Management Studies Delhi University and has further done a Post Graduate Diploma from AIMA in IT systems, DOEACC A level certified and a Post Graduate Diploma in Operations Management from IGNOU after Bachelors in Science. He is a Prince 2 certified professional, Microsoft Certified Professional and a Oracle Certified professional and has 19 years of global experience and is an award winning Global CIO with a strong technical and managerial background and has done numerous global rollouts of Enterprise Information Systems -ERP/CRM/BI and M2M/Mobility and IoT solutions which have been widely acknowledged and awarded in different forums. He is currently pursuing his Doctorate in Information Technology Management with focus on IoT strategies and technologies and has published papers on IoT in Springer and IEEEXplore.

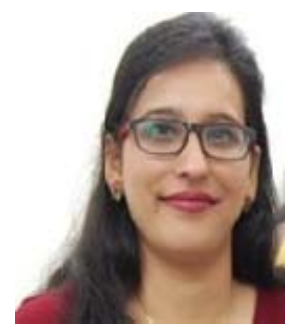

Dr. Loveleen Gaur is PhD in Computer Applications, M.Phil. in Computer Applications and M.C.A. A experience of eleven years in academics and is actively involved in research and academic activities. She has attended many international conferences and has numerous national and international publications to her credit and has published her research papers with refereed journals listed in Cabell's directory like "Journal of Strategic E- Commerce" of Allied Academies Inc., U.S.A and "Review of Business Research" of International Academy of Business and Economics. She is serving on the editorial board for the International Journal of "Global Digital .Business Association”. She is also serving as paper reviewer for many National and International Journals. She Received 'Best paper Award' by Smt. Sheila Dixit (Chief Minister, Delhi) for her research paper published in "Management Review", Journal of Delhi Management Association (DMA).She Received 'Distinguished Research Award' for her research paper published in International "Journal of Strategic E-Commerce”, of Allied Academies Inc., U.S.A. She is also the author of two books in the area of Computer Applications and has contributed chapters for various management books.

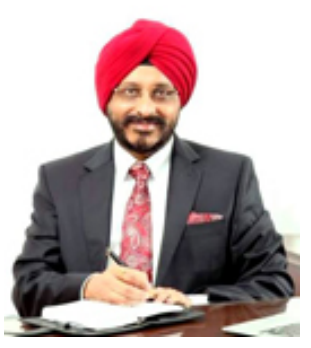

Prof Gurinder Singh is PhD in International Business and done his Masters from IIFT.He has more than 20 years of experience in Strategic Management, teaching, consultancy and research. He has launched new organizations in India, UK, USA, France, Germany, Australia, and African countries, Singapore, Dubai and Taiwan. He has been honoured with prestigious National and International "Life Time Achievement Award \& Gold Medal” ,"Rashtriya Samman Puruskar Award”, "Siksha Bharti Award by IEDRA", "Ambassador of peace Award”, "Gem of India", and "Arch of Excellence Award". He is the youngest Professor in the area of Management and is known in the field of academics as an institution builder, writer, professor, distinguished academician, trainer and international business manager. He has written numerous books, research papers and presented in the Harvard Business School, Thunderbird Business School USA, New York University, Purdue University, St Cloud University, Essex University, University of Leeds, University of East London and many other prestigious Universities. 